\title{
Glycogen-gold nanohybrid escalates the potency of silymarin
}

\author{
This article was published in the following Dove Press journal: \\ International Journal of Nanomedicine \\ 25 September 2017 \\ Number of times this article has been viewed
}

\section{Raghuram Kandimalla' \\ Suvakanta Dash ${ }^{2}$ \\ Ashim Chandra Bhowal ${ }^{3}$ \\ Sanjeeb Kalita' \\ Narayan Chandra Talukdar' \\ Sarathi Kundu ${ }^{3}$ \\ Jibon Kotoky ${ }^{1,4}$}

'Drug Discovery Lab, Institute of Advanced Study in Science and Technology, ${ }^{2}$ Girijananda Choudhury Institute of Pharmaceutical Sciences, ${ }^{3}$ Soft Nano Laboratory, Institute of Advanced Study in Science and Technology, ${ }^{4}$ National Institute of Pharmaceutical Education and Research, Guwahati, India
Correspondence: Raghuram Kandimalla; Sanjeeb Kalita

Drug Discovery Lab, Institute of

Advanced Study in Science and

Technology, Paschim Boragaon, Garchuk,

Guwahati 781035, Assam, India

Tel +9l 9435197316 ;

+91 9085936018

Email raghuram.pharma@gmail.com; sanju.kalita@gmail.com

\begin{abstract}
In this study, a glycogen-gold nanohybrid was fabricated to enhance the potency of a promising hepatoprotective agent silymarin (Sly) by improving its solubility and gut permeation. By utilizing a facile green chemistry approach, biogenic gold nanoparticles were synthesized from Annona reticulata leaf phytoconstituents in combination with Sly (SGNPs). Further, the SGNPs were aggregated in glycogen biopolymer to yield the therapeutic nanohybrids (GSGNPs). Transmission electron microscopy, UV-Vis spectroscopy, X-ray diffraction, and Fourier transform infrared spectroscopy analysis confirmed the successful formation and conjugation of both SGNPs and GSGNPs. The fabricated nanohybrids showed significant protection against $\mathrm{CCl}_{4}$ induced hepatic injury in Wistar rats and maintained natural antioxidant (superoxide dismutase and catalase) levels. Animals treated with GSGNPs (10 mg/kg) and SGNPs (20 mg/kg) retained usual hepatic functions with routine levels of hepatobiliary enzymes (aspartate transferase, alanine transaminase, alkaline phosphatase, and lactate dehydrogenase) and inflammatory markers (interleukin- $1 \beta$ and tumor necrosis factor- $\alpha$ ) with minimal lipid peroxidation, whereas those treated with $100 \mathrm{mg} / \mathrm{kg}$ of Sly showed the similar effect. These results were also supported by histopathology of the livers where pronounced hepatoprotection with normal hepatic physiology and negligible inflammatory infiltrate were observed. Significant higher plasma $C_{\max }$ supported the enhanced bioavailability of Sly upon GSGNPs treatment compared to SGNPs and free Sly. Graphite furnace atomic absorption spectrophotometry analysis also substantiated the efficient delivery of GSGNPs over SGNPs. The fabricated therapeutic nanohybrids were also found to be biocompatible toward human erythrocytes and L929 mouse fibroblast cells. Overall, due to increased solubility, bioavailability and profuse gut absorption; GSGNPs demonstrated tenfold enhanced potency compared to free Sly.
\end{abstract}

Keywords: silymarin, Annona reticulata, glycogen-gold, nanohybrid, potency, hepatoprotection

\section{Introduction}

The liver, the second largest organ in human body, involves in vital functions like cleansing blood, vitamin synthesis, and drug metabolism along with regulation of body fuel, cholesterol, and hormones. The liver is adversely affected by the vast number of reactive oxygen species (ROS) generated through liver-attacking viruses, harmful chemicals, and chronic alcoholism. ${ }^{1}$ Silymarin (Sly) is a flavonoid antioxidant widely used for the treatment of various liver ailments like hepatitis, cirrhosis, and fatty liver. Therapeutic effects of the Sly are caused by its primary active form silybin, which are hindered by its poor gut absorption, solubility, and stability in gastric juices. Attempts have been made to improve the bioavailability of Sly through nanoencapsulation, but further interventions are still required to fabricate the potent nanohybrids. ${ }^{2-4}$ The present study was aimed to develop a nanohybrid system to improve the solubility, bioavailability, and potency of the Sly molecule. In this study, the inherent reducing 
capability of Sly was exploited for tethering the same on the gold nanoparticle (GNP) surface in the presence of glycogen (Gly). We postulate that stable biogenic GNP-drug cargo escalates the potency of the Sly by increasing the solubility and bioavailability.

Inorganic nanoparticle and polysaccharide polymer conjugates are reported to have tremendous applications in recent nano-biotechnology advancements. Surface engineering of inorganic nanoparticles with organic moieties results in improvised physicochemical properties with beneficial functionalities. ${ }^{5}$ The inherent beneficial traits of these nanoparticles can be exploited for the development of advanced molecular drug delivery vehicle where current therapeutic regime fails to exhibit the desired effects. Drugfunctionalized nanoparticle system holds immense potential for novel delivery, imaging, theranostic, and photodynamic therapy applications. Chemically inert biocompatible nanoparticles are exploited as functional drug carriers which were reported to reduce the toxic side effects of the drug candidate with increased potency and therapeutic index. ${ }^{2}$ Being a physicochemically inert material with desirable stability and biocompatibility, bioactive molecule-conjugated GNPs hold promises for a wide range of biomedical therapeutic applications. ${ }^{6}$ GNPs were reported to improve the hepatoprotective, antimicrobial, and anticancer efficacy of the therapeutic bioactive molecules upon conjugation. ${ }^{2,7-9}$

Synthesis methods, templates, and reducing and stabilizing agents play a crucial role in the fabrication of GNPs with biocompatible attributes. Plant phytochemicals of tea leaves, Morinda citrifolia roots, and Pelargonium graveolens leaves were reported as green nano-factory for the synthesis of biocompatible GNPs and to be preferred over chemically or physically synthesized counterparts. ${ }^{10-13}$ Annona reticulata (Annonaceae) is a small, deciduous tree commonly called Ramphal, Bullock's heart, or custard apple, which is native to India, West Indies, and tropical America, mainly cultivated for fruit production. ${ }^{14,15}$ This plant is a good source of different phytochemicals like acetogenins, cycloreticulins A and B, cyclooctapeptides, cycloreticulin C, glabrin A, and cyclopeptides. ${ }^{15-17}$ In this study, GNPs were synthesized using $A$. reticulata $\mathrm{L}$. leaf aqueous extract as a reducing agent.

GNPs functionalized with molecular polysaccharide (Gly, starch, chitosan, etc.) can be used as a model drug delivery vehicle to produce the desired efficacy of therapeutic moieties. Gly is the branched storage form of glucose found primarily in the liver, which can be broken down into glucose molecules when there is an energy requirement in the body. Spherical, dendrimer-structured $\beta$ macromolecules of Gly (20-40 nm) can act as a convenient nano-reactor for the growth and stabilization of metallic nanoparticles. ${ }^{18}$ The inherent aggregation behavior of the biogenic GNPs in Gly leads to the formation of Gly-gold bioconjugates. This system can be exploited as a nano-carrier for therapeutic molecule delivery to hepatic cells and other biomedical applications.

\section{Materials and methods Materials}

Sly, chloroauric acid $\left(\mathrm{HAuCl}_{4}\right)$, and Gly were purchased from Sigma-Aldrich (St Louis, MO, USA). Biochemical kits for enzyme estimation were procured from Accurex (Mumbai, India), and ELISA kits for interleukin measurement were obtained from R\&D Systems (Minneapolis, MN, USA). All the other chemicals used in this study were of analytical grade and purchased from Sigma-Aldrich and Merck (Darmstadt, Germany).

\section{Plant collection and identification, and preparation of extract}

A. reticulata leaves were collected from Kamrup district $\left(26.3333^{\circ} \mathrm{N}, 91.2500^{\circ} \mathrm{E}\right)$, Assam, India, in January 2016. The plant was identified by a taxonomist at North East India Ayurvedic Research Institute, Guwahati, Assam, India. A voucher specimen (1401/IASST/2015-16) was deposited at the Drug Discovery Lab, Institute of Advanced Study in Science and Technology (IASST), Guwahati, Assam, India, for future reference. The leaves were shade-dried and ground into a coarse powder. For the extraction, the plant powder was macerated with deionized water for $24 \mathrm{~h}$. Further, the water extract was filtered through Whatman filter paper, and the resulting solution was lyophilized to get a fine aqueous extract of $A$. reticulata leaves (ARLWE). Further, the ARLWE was stored at $-20^{\circ} \mathrm{C}$ and used within 4 months after extraction.

\section{Synthesis of nanohybrids}

To $6 \mathrm{~mL}$ of $0.4 \mathrm{mM}$ Sly (dissolved in $0.1 \mathrm{mM}$ sodium hydroxide), $3.2 \mathrm{~mL}$ of $1 \mathrm{mM} \mathrm{HAuCl}_{4}$ and $0.4 \mathrm{~mL}$ of $1 \%$ ARLWE were added. The total reaction mixture was stirred for $10 \mathrm{~min}$ at room temperature using a magnetic stirrer. The formation of Sly-tethered gold nanoparticles (SGNPs) was confirmed by the color change of reaction mixture to different hues of red color. The solution containing the SGNPs was lyophilized, and the resulting powder was stored at $-20^{\circ} \mathrm{C}$. This method was adopted from Kabir et al with further modifications. ${ }^{2}$ GNPs were also prepared without Sly for the confirmation of successful formation of SGNPs and for comparison with SGNPs in characterization techniques. To prepare the Gly- and Sly-tethered gold nanoparticles (GSGNPs), 
the above-mentioned steps were followed by the dropwise addition of $0.5 \%$ Gly solution. The reaction mixture was stirred using a magnetic stirrer for $24 \mathrm{~h}$ at room temperature. The resulting solution was lyophilized, and GSGNPs (nanohybrids) were stored at $-20^{\circ} \mathrm{C}$ for further use.

\section{Drug-loading efficiency evaluation}

The GSGNP-containing solution was centrifuged at 7,500 rpm for $30 \mathrm{~min}$, and the obtained pellet was separated from the supernatant and redispersed in Milli-Q water. The concentration of Sly was determined by measuring ultraviolet (UV) absorbance at $300 \mathrm{~nm}$ using UV-visible (UV-Vis) spectroscopy, and the loading percentage of Sly in GSGNPs was calculated by the following formula: ${ }^{19}$

$$
\text { Loading efficacy }(\%)=\frac{A-B}{A} \times 100
$$

where $\mathrm{A}=$ total amount of silymarin added; $\mathrm{B}=$ amount of silymarin in redispersed pellet.

\section{Characterization of nanohybrids}

The morphology and size of the GSGNPs were investigated using transmission electron microscopy (TEM) (JEOL 2100 UHR). UV-Vis spectroscopic measurements were carried out on a Carry 100 BIO UV-Vis spectrophotometer (Varian, Palo Alto, CA, USA) to study the drug loading and Gly capping. Bruker D8 ADVANCE X-ray powder diffractometer (Bruker AXS Inc.) was used to perform the X-ray diffraction (XRD) analysis of the SGNPs and GSGNPs. Fourier transform infrared (FT-IR) spectroscopy was performed to determine the functional groups present on SGNPs and GSGNPs.

\section{Biocompatibility evaluation of nanohybrids}

The biocompatibility of the prepared SGNPs and GSGNPs was evaluated against human red blood cells (RBCs) and L929 cell lines. ${ }^{20-22}$ The protocol for experiments on human blood samples was approved by the Institutional Human Ethics Committee (IHEC), IASST, Guwahati, Assam, India. Informed consent was obtained from the human volunteer to conduct the experiments.

\section{Hemocompatibility assay}

Blood $(10 \mathrm{~mL})$ was collected in EDTA tubes from a healthy human volunteer and used for test within $3 \mathrm{~h}$ after collection. SGNPs and GSGNPs at various concentrations $(0.1$, $0.25,0.5,0.75$, and $1 \mathrm{mg} / \mathrm{mL}$ ) were incubated for $10 \mathrm{~min}$, and $1,6,12$, and $24 \mathrm{~h}$ at $37^{\circ} \mathrm{C}$ in siliconized tube along with $10 \mathrm{~mL}$ of blood (diluted with saline in 1:9 ratio). After completion of the incubation period, all the tubes were centrifuged at 1,500 rpm for $10 \mathrm{~min}$. The absorbance of the supernatant was measured at $545 \mathrm{~nm}$ using a UV-Vis spectrophotometer (UV 1800; Shimadzu, Kyoto, Japan). The percentage of hemolysis was calculated using the following formula:

$$
\text { Hemolysis }(\%)=\left(\frac{\mathrm{Abs}_{\text {sample }}-\mathrm{Abs}_{- \text {ve control }}}{A b s_{+ \text {ve control }}-\mathrm{Abs}_{- \text {ve control }}}\right) \times 100
$$

\section{Field emission scanning electron microscopy (FE-SEM) analysis of RBCs}

FE-SEM analysis of RBCs was performed to observe the morphology of RBCs after incubation with SGNPs and GSGNPs (1 mg/mL) for $24 \mathrm{~h}$. Briefly, RBC pellet from the above experiment was collected and used for FE-SEM analysis. The RBCs from all the treatment groups were fixed in 3\% glutaraldehyde for $4 \mathrm{~h}$. Further, cells were washed with $0.2 \mathrm{mM}$ phosphate buffer saline (PBS) and incubated in the same PBS for $6 \mathrm{~h}$. After the incubation with PBS, the cells were subjected to dehydration process with gradient acetone $(30,50,70,90,95$, and $100 \%)$ with $10 \mathrm{~min}$ of incubation in each concentration and at last with dry acetone. The RBCs were then incubated with tetramethyl silane for $15 \mathrm{~min}$ and evaporated to dryness until a fine powder formed in a desiccator. Further, the RBCs from different treatment groups were observed for morphological changes using FE-SEM.

\section{Cytocompatibility assay}

L929 mouse fibroblast cells were procured from the National Center for Cell Science (NCCS), Pune, Maharashtra, India. MTT assay was performed to determine the cytotoxic concentrations of SGNPs and GSGNPs. ${ }^{23}$ Briefly, L929 cells were trypsinized and seeded in a 96 -well plate $\left(5 \times 10^{3}\right.$ cells/ well) and incubated in a $\mathrm{CO}_{2}$ incubator at $37^{\circ} \mathrm{C}$ for $24 \mathrm{~h}$. After $24 \mathrm{~h}$, the culture medium was replaced with a new medium, and SGNPs and GSGNPs at different concentrations $(5,25,50,125,250$, and $500 \mu \mathrm{g} / \mathrm{mL})$ were added to the wells. After $24 \mathrm{~h}$ of further incubation, $20 \mu \mathrm{L}$ of $4 \mathrm{mg} / \mathrm{mL}$ MTT ( $\mathrm{pH}$ 7.4) was added to each well. The plate was further incubated for an additional $4 \mathrm{~h}$, and the supernatant was removed followed by the addition of $100 \mu \mathrm{L}$ of DMSO to each well. After $30 \mathrm{~min}$ of incubation, the absorbance of the dissolved formazan was recorded at $570 \mathrm{~nm}$ by using a microplate reader (Thermo Fisher Scientific, Waltham, MA, 
USA). The percentage growth inhibition was calculated by using the following formula:

Growth inhibition (\%)

$$
=\left(\frac{100-\text { Mean OD of individual test group }}{\text { Mean OD of control group }}\right) \times 100
$$

\section{Evaluation of the hepatoprotective ability of nanohybrids against $\mathrm{CCl}_{4}$-induced acute liver damage}

Animals

Male Wistar rats (4 months old) weighing 150-160 g were selected for the study and maintained at standard room conditions $\left(24^{\circ} \mathrm{C} \pm 1^{\circ} \mathrm{C}\right.$ temperature, $45 \%-55 \%$ relative humidity, and 12:12 h dark/light cycle). Animals had free access to water and standard pellet diet (Provimi Animal Nutrition Pvt. Ltd., Bangalore, Karnataka, India) throughout the experiment. The experimental protocol was approved by the Institutional Animal Ethical Committee (IAEC) of IASST, Guwahati, Assam, India (IASST/IAEC/2015-16/661), and performed in accordance with the Committee for the Purpose of Control and Supervision of Experiments on Animals (CPCSEA) guidelines.

\section{$\mathrm{CCl}_{4}$-induced acute liver damage}

A total of 42 animals were randomly divided into seven groups of six animals each. All the drug treatments were continued for 14 days, and on the 14th day, a single dose of $\mathrm{CCl}_{4}(1 \mathrm{~mL} / \mathrm{kg})$, in 1:1 dilution with olive oil, was given by intraperitoneal route.

\section{Drug treatment schedule}

Group I: Animals treated with distilled water (DW) for 14 days orally + olive oil $(1 \mathrm{~mL} / \mathrm{kg})$ on the 14 th day.

Group II: Animals treated with $0.3 \%$ carboxy methyl cellulose (CMC) for 14 days orally $+\mathrm{CCl}_{4}(1 \mathrm{~mL} / \mathrm{kg})$ on the 14th day.

Group III: Animals treated with Sly $100 \mathrm{mg} / \mathrm{kg}$ orally (suspended in $0.3 \% \mathrm{CMC})+\mathrm{CCl}_{4}(1 \mathrm{~mL} / \mathrm{kg})$ on the 14 th day.

Groups IV and V: Animals treated with SGNPs at 10 and $20 \mathrm{mg} / \mathrm{kg}$ orally $+\mathrm{CCl}_{4}(1 \mathrm{~mL} / \mathrm{kg})$ on the 14 th day.

Groups VI and VII: Animals treated with GSGNPs at 10 and $20 \mathrm{mg} / \mathrm{kg}$ orally $+\mathrm{CCl}_{4}(1 \mathrm{~mL} / \mathrm{kg})$ on the 14 th day.

Note: In the case of SGNPs and GSGNPs, an equivalent dose of Sly was administered.

After $48 \mathrm{~h}$ of $\mathrm{CCl}_{4}$ administration, blood was collected from animals through retro-orbital route under mild anesthesia. After blood collection, all the animals from various groups were sacrificed through decapitation, and the livers were collected immediately. Each collected liver was divided into three parts. One part was stored in $10 \%$ buffered formaldehyde for histopathology analysis, the second part was frozen in liquid nitrogen for biochemical estimation, and the third part was collected in empty Falcon tubes to measure the gold concentration through atomic absorption spectroscopy (AAS).

\section{Evaluation of serum biochemical estimation}

Blood was allowed to clot, and serum was separated by centrifugation at 1,500 rpm for $10 \mathrm{~min}$. The levels of aspartate transferase (AST), alanine transaminase (ALT), alkaline phosphatase (ALP), and lactate dehydrogenase (LDH) were measured using commercially available kits as per the instructions given by the manufacturer (Accurex). All the experiments were performed in a cold room $\left(4^{\circ} \mathrm{C}\right) .^{24,25}$

\section{Evaluation of liver antioxidant enzyme levels and lipid peroxidation}

The liver homogenate was prepared with $50 \mathrm{mM}$ cold potassium phosphate buffer ( $\mathrm{pH} 7.4$ ) and centrifuged at 3,000 rpm for $15 \mathrm{~min}$. The supernatant was collected for the estimation of superoxide dismutase (SOD) and catalase (CAT) using assay kits from Cayman (Ann Arbor, MI, USA), and thiobarbituric acid-reacting substance, which was performed as per the procedure of Kandimalla et al. ${ }^{26}$ All the experiments were conducted in a cold room $\left(4^{\circ} \mathrm{C}\right)$.

\section{Measurement of gold concentration in the livers from different treatment groups}

A part of the liver ( $1 \mathrm{~g}$ ) was homogenized and dried completely in a hot air oven at $60^{\circ} \mathrm{C}-70^{\circ} \mathrm{C}$. Further, the dried tissues were digested using 30\% hydrogen peroxide and $0.25 \mathrm{~N}$ trace metal-free nitric acid at $50^{\circ} \mathrm{C}-60^{\circ} \mathrm{C}$ until a white ash formed. The gold concentration was estimated in the digested ashes through graphite furnace atomic absorption spectrophotometry (GF-AAS) (PerkinElmer Model PinAAcle $900 \mathrm{H}$ ). The gold concentration was quantified by using the standard calibration curve of the elemental gold standard (Sigma-Aldrich). All the GF-AAS analyses were conducted at a temperature of $1,800^{\circ} \mathrm{C}{ }^{23}$

\section{Histopathology examination of the liver from various treatment groups}

The liver tissues were collected in 10\% buffered formaldehyde from animals in different treatment groups and preserved for at least $24 \mathrm{~h}$. After subjected to dehydration 
gradually with ethanol (70\%-100\%), tissues were cleared in xylene and embedded in paraffin to prepare blocks. Sections of $5 \mu \mathrm{m}$ were prepared by a Leica RM 2016 rotary microtome (Leica Instruments Ltd., Shanghai, People's Republic of China) and stained with hematoxylin and eosin. Slides were examined under a light microscope (Digital Imaging System; Leica Microsystems, Wetzlar, Germany) at $10 \times$ magnification to observe the histopathological changes. ${ }^{27,28}$

\section{Determination of plasma concentration of Sly in rats}

Male Wistar rats weighing 200-250 g were used for this study. All the animals were housed in standard laboratory conditions $\left(25^{\circ} \mathrm{C} \pm 2{ }^{\circ} \mathrm{C}, 55 \% \pm 5 \%\right.$ relative humidity) and had free access to standard pellet diet (Provimi Animal Nutrition Pvt. Ltd.) and water ad libitum. Animals were randomly divided into four groups of six animals each. Animals were fasted overnight before the drug treatments given as per the following schedule:

Group I: Animals fed with free Sly orally

Group II: Animals fed with silybon tablets orally

Group III: Animals fed with SGNPs orally

Group IV: Animals fed with GSGNPs orally

Note: All rats were treated with an equivalent dose of $20 \mathrm{mg} / \mathrm{kg}$ Sly.

Blood was withdrawn at different time intervals $(0,1,3,5$, 7, 9, and $12 \mathrm{~h}$ ) in EDTA-coated micro-centrifuge tubes. Plasma was separated by centrifuging the blood at 2,000 rpm for $10 \mathrm{~min}$ at $4^{\circ} \mathrm{C}$. To determine the plasma concentration of the Sly, $1 \mathrm{~mL}$ of ethyl acetate was added to plasma and vortexed for $1 \mathrm{~min}$. The resulting solution was centrifuged at 10,000 rpm for $10 \mathrm{~min}$. The supernatant was collected, dried under liquid nitrogen, and reconstituted in $100 \mu \mathrm{L}$ of methanol to be used for HPLC analysis (Varian) with Hypersil BDS RP-C18 column (Thermo Fisher Scientific) of dimensions $5 \mathrm{~mm}$, $250 \times 4.6 \mathrm{~mm}$. Methanol and water at 46:54 ratio (v/v) were used as the mobile phase, and the flow rate was maintained at $0.8 \mathrm{~mL} / \mathrm{min}$. The effluents were monitored at $287 \mathrm{~nm}^{29}$

\section{Storage stability of nanohybrids}

The nanohybrids (GSGNPs) were stored at static conditions under $4^{\circ} \mathrm{C}$ and $25^{\circ} \mathrm{C}$ for a 6 -month period. The stability of the nanohybrids was confirmed by comparing the initial particle size with that obtained after 6 months. ${ }^{20}$

\section{Statistical analysis}

All the results are expressed as mean \pm SD. One-way ANOVA followed by Tukey's multiple comparison tests was used to compare the different parameters between the groups. A $P$-value $<0.05$ was considered as significant. All the statistical analyses were performed by using Prism 6.0 software.

\section{Results}

\section{Characterization of nanohybrids}

In this study, we synthesized SGNPs via magnetic stirring at room temperature in the presence of gold precursor, Sly, and ARLWE. Changes in the color from pale yellow to different ranges of red hues confirmed the successful formation of SGNPs. Auric ions $\left(\mathrm{Au}^{3+}\right)$ were reduced by the ARLWE and Sly into gold atoms $\left(\mathrm{Au}^{0}\right)$. The phytochemicals like flavonoids, terpenoids, and a class of alkaloids acted as reducing and stabilizing agents in the formation of SGNPs. We further aggregated the SGNPs in Gly matrix to form nanohybrids (GSGNPs). TEM images of GSGNPs revealed the presence of both spherical- and triangle-shaped mixed nanohybrids. Selected area electron diffraction pattern and ultrahigh-resolution TEM results confirmed the crystalline nature of the prepared nanohybrids (Figure $1 \mathrm{Aa}-\mathrm{d}$ ). The average particle size of GSGNPs was found to be $22.7 \pm 6.4 \mathrm{~nm}$. The percentage loading efficiency of Sly on GSGNPs was found to be $82 \pm 1.9 \%$.

Attachment or conjugation of different drug molecules with nanoparticles can be confirmed by UV-Vis absorption spectroscopy analysis. Figure 1B depicts the absorption peaks of GNPs, plant extract (ARLWE), Gly, Sly, SGNPs, and GSGNPs. We observed the plasmonic absorption peak from bare GNPs at $540 \mathrm{~nm}$ (Figure 1B). The absorption peak observed at $268 \mathrm{~nm}$ is from the plant extract, whereas peaks observed at 247 and $300 \mathrm{~nm}$ are from Sly and the peak observed at $260 \mathrm{~nm}$ is from Gly. However, when the GNPs were synthesized in the presence of Sly (SGNPs) along with the ARLWE, the plasmonic absorption peak of GNPs shifted to $536 \mathrm{~nm}$ along with peaks at 253 and $287 \mathrm{~nm}$. This shift in the absorption peaks of the nanoparticles indicates the conjugation of Sly on the GNP surfaces. The aggregation of SGNPs in the Gly matrix (GSGNPs) resulted in absorption peaks at 538 and $272 \mathrm{~nm}$. We believe that the new peak at $272 \mathrm{~nm}$ is due to the combined absorption effect of Sly and Gly on the GNP surfaces. Significant changes in the absorption peaks confirmed the successful conjugation of both Sly and Gly on GNP surfaces.

The conjugation of Sly and Gly on GNP surfaces was further confirmed by XRD analysis. Figure 2A illustrates the XRD spectra of the glass substrate, Sly, Gly, GNPs, SGNPs, and GSGNPs. Glass substrate showed a broad amorphous 
A a

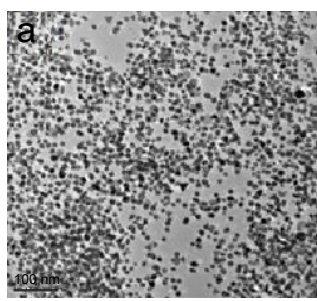

c

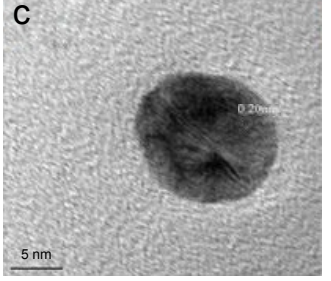

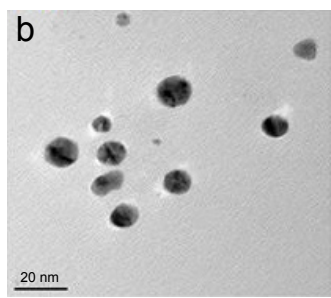

d

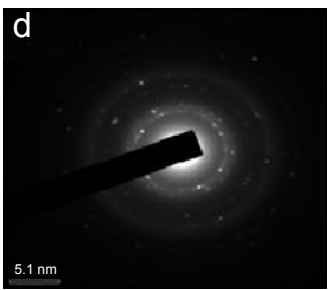

B

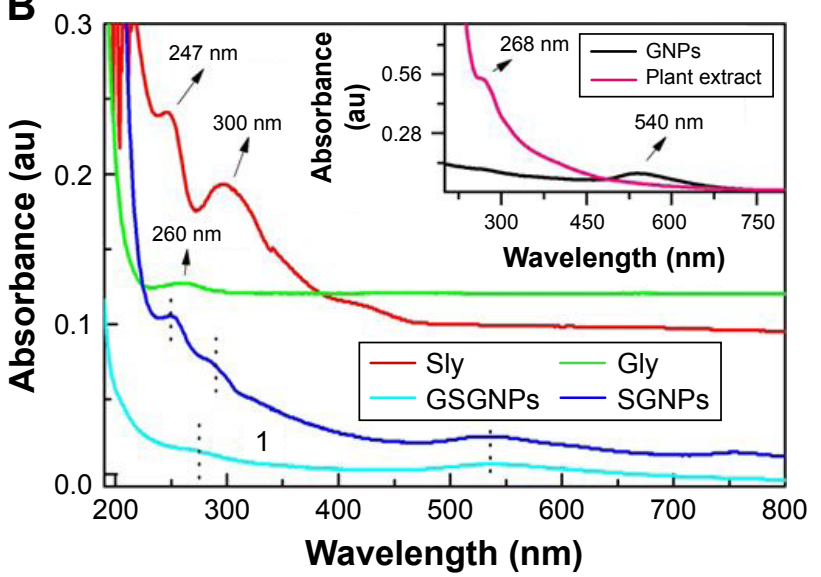

Figure I (A) a-c: Transmission electron microscopy images of GSGNPs; d: SAED pattern. (B) UV-Vis spectroscopy of Sly, Gly, SGNPs, GSGNPs, water extract of Annona reticulata leaves (plant extract), and bare GNPs.

Abbreviations: GSGNPs, SGNPs aggregated in Gly; SAED, selected area electron diffraction pattern; Sly, silymarin; Gly, glycogen; SGNPs, Sly-tethered GNPs; GNPs, gold nanoparticles; UV-Vis, ultraviolet-visible.

peak at $\sim 24.35^{\circ}$ and Gly diffraction peak centered at $17^{\circ}$, whereas Sly showed different small peaks overlapping with the broad peak obtained at $20^{\circ}$. XRD peak for GNPs was observed at $\sim 38.15^{\circ}$, which signifies the reflection of X-ray from (111) plane having fcc structure of the GNPs. However, two additional diffraction peaks at $\sim 28.06^{\circ}$ and $40.40^{\circ}$ were also observed, which were also present in the XRD pattern of ARLWE (data not shown). SGNPs showed diffraction peaks at $22.95^{\circ}$ and $38.15^{\circ}$, which confirmed the successful tethering of Sly on GNPs. Diffraction peaks observed at $21.41^{\circ}$ and $38.20^{\circ}$ illustrated the formation of GSGNPs. We believe the new peak at $21.41^{\circ}$ is due to the combined effect of both Sly and Gly. Hence, XRD studies clearly indicate the presence of both Sly and Gly with GNPs and support the previously discussed UV-Vis absorption spectroscopy results.

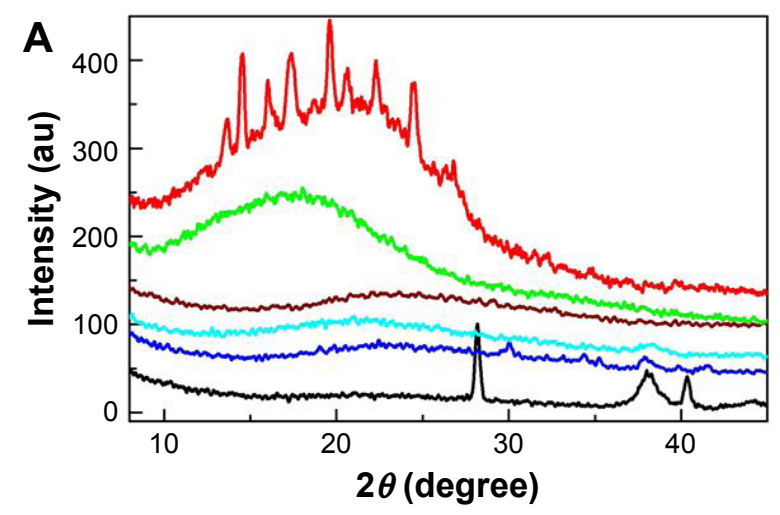

\begin{tabular}{|lll|}
\hline Glass & Gly & Sly \\
GNPs & - SGNPs & GSGNPs \\
\hline
\end{tabular}

FT-IR molecular spectroscopy provides detailed information on conjugation of nanoparticles with drug molecules. Three vibrational bands of Sly were observed at 1,633, 1,510, and $1,271 \mathrm{~cm}^{-1}$ which correspond to $-\mathrm{C}=\mathrm{O}$ (in-ring), $\mathrm{C}=\mathrm{C}$ (in-ring), and $\mathrm{C}-\mathrm{O}$ of polyols group, respectively. The bands at 1,560 and 1,262 $\mathrm{cm}^{-1}$ (green curve) belong to Gly. SGNPs infrared bands (blue curve) were observed at 1,635, 1,508, and $1,263 \mathrm{~cm}^{-1}$. It is worth mentioning that no such bands were observed in the case of GNPs (data not shown). The vibrations bands (cyan curve) for GSGNPs were positioned at $1,645,1,558,1,507$, and $1,261 \mathrm{~cm}^{-1}$. All these bands matched with individual vibrational bands of Sly and Gly peaks with a little shift in peak positions. These findings demonstrate the successful attachment of both Sly and Gly on GNPs, which is in accordance with UV-Vis and XRD observations (Figure 2B).

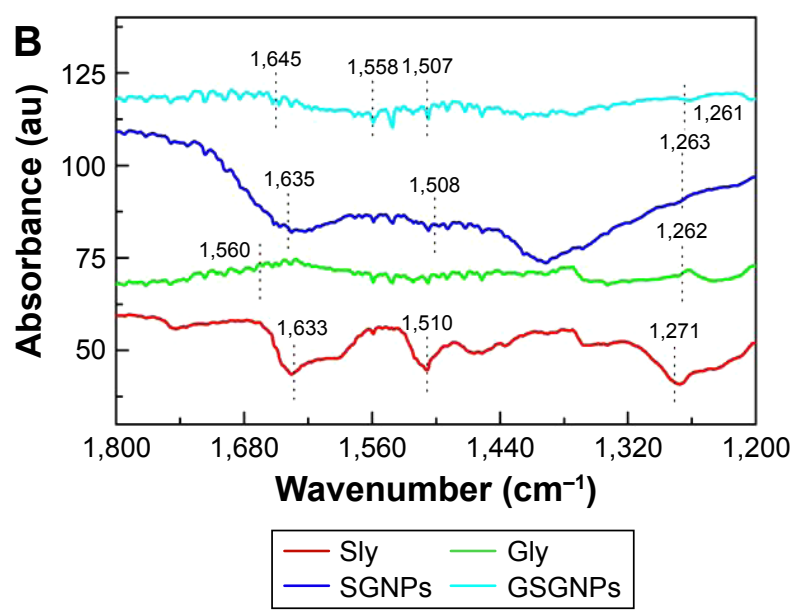

Figure 2 (A) X-ray diffraction analysis of Sly, Gly, SGNPs, GSGNPs, and bare GNPs. (B) Fourier transform infrared spectroscopy of Sly, Gly, SGNPs, and GSGNPs. Abbreviations: Sly, silymarin; Gly, glycogen; SGNPs, Sly-tethered GNPs; GSGNPs, SGNPs aggregated in Gly; GNPs, gold nanoparticles. 

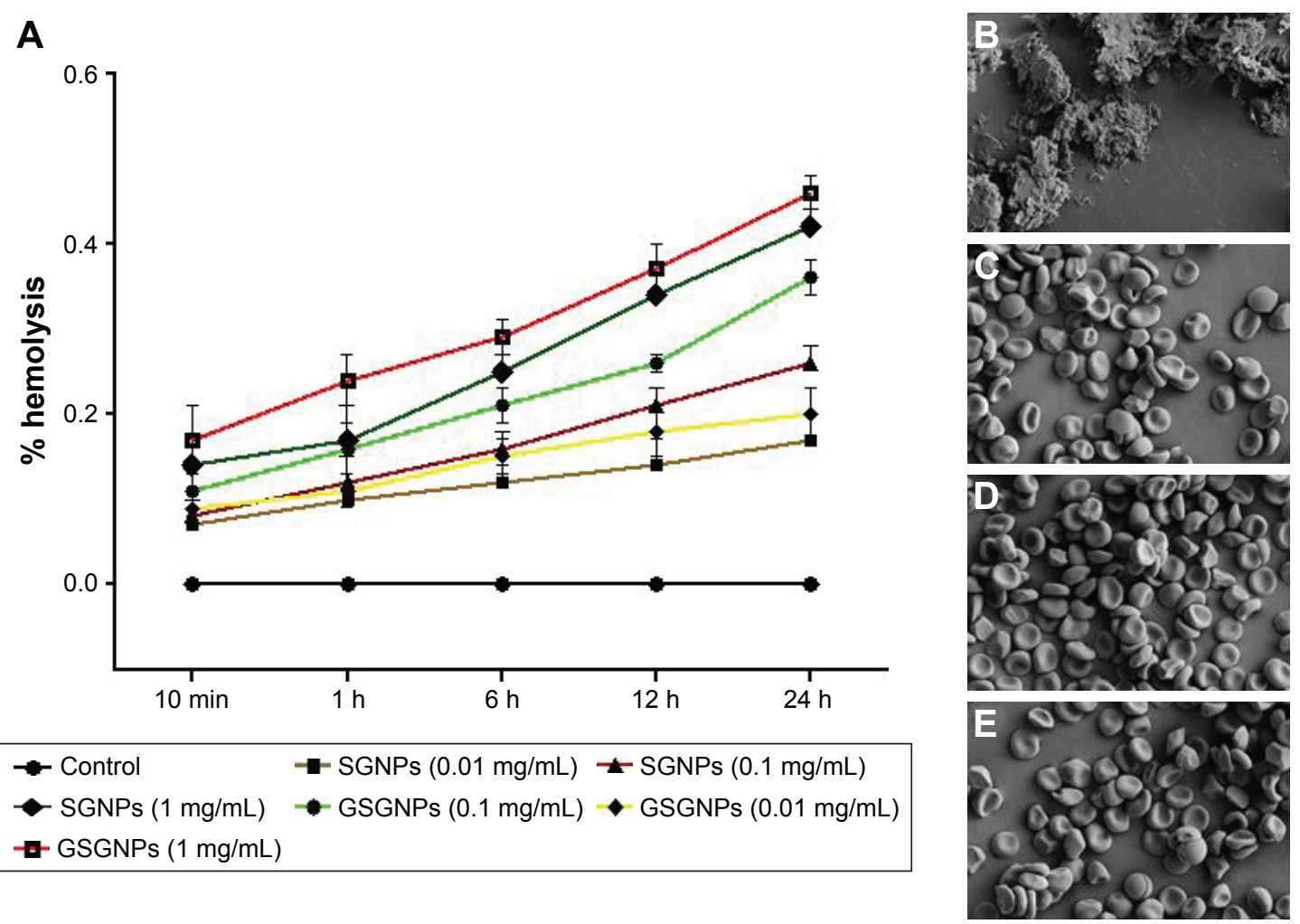

Figure 3 (A) Time-dependent effect of different concentrations of SGNPs and GSGNPs on \% hemolysis. FE-SEM analysis of RBCs treated with (B) distilled water, (C) normal saline, (D) SGNPs (I mg/mL), and (E) GSGNPs (I mg/mL). All the results are expressed as mean $\pm S D(\mathrm{n}=3)$. Magnification 5,000x.

Abbreviations: SGNPs, silymarin-tethered gold nanoparticles; GSGNPs, SGNPs aggregated in glycogen; FE-SEM, field emission scanning electron microscopy; RBCs, red blood cells.

\section{Biocompatibility of nanohybrids Hemocompatibility \\ $\%$ hemolysis}

The hemolytic activity of the SGNPs and GSGNPs was screened against human erythrocytes. The results are expressed as \% hemolysis and represented in mean \pm SD of three replicates. SGNPs and GSGNPs produced very mild hemolysis at a concentration up to $1 \mathrm{mg} / \mathrm{mL}$ (Figure 3A), which is within the permissible limit of blood-contacting biomaterials (5\%). Both SGNPs and GSGNPs were found to be nontoxic and biocompatible to human erythrocytes.

\section{FE-SEM analysis of RBCs}

Membrane-active toxic substances alter the shape of RBCs upon interaction with them. FE-SEM images of RBCs from various treatment groups revealed that SGNPs and GSGNPs did not produce any adverse effect on the structural integrity of RBCs (Figure 3B-E). DW treatment resulted in complete lysis of RBCs, whereas PBS-treated RBCs maintained their normal morphology. The results of this study explain that the fabricated nanohybrids are safe and did not produce any deleterious effects upon treatment.

\section{Cytocompatibility}

SGNPs and GSGNPs at different concentrations did not induce any toxic effect on L929 mouse fibroblastic cells. At highest concentration $(250 \mu \mathrm{g} / \mathrm{mL})$, SGNPs and GSGNPs resulted in $92.9 \%$ and $92.7 \%$ viability of L929 cells, respectively (Figure 4). The acceptable cytotoxicity of biomedical substances is $75 \%$ toward mammalian cells, which indicates the nontoxic attribute of SGNPs and GSGNPs.

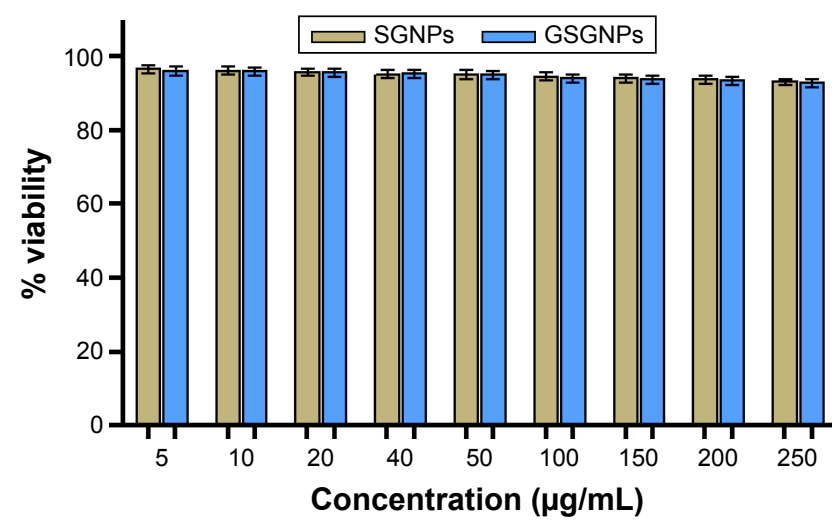

Figure 4 Effect of different concentrations of SGNPs and GSGNPs on \% cell viability of $L 929$ cells. All the results are expressed as mean $\pm S D(n=3)$.

Abbreviations: SGNPs, silymarin-tethered gold nanoparticles; GSGNPs, SGNPs aggregated in glycogen. 
Table I Effect of different drug treatments on serum liver function marker levels in $\mathrm{CCl}_{4}$-intoxicated rats

\begin{tabular}{|c|c|c|c|c|c|}
\hline Group & Treatment & AST (IU/I) & ALT (IU/I) & ALP (IU/I) & LDH (U/I) \\
\hline I & $\mathrm{DW}+$ olive oil $(\mathrm{I} \mathrm{mL} / \mathrm{kg})$ & $39.5 \pm 2.3$ & $37.1 \pm 2.1$ & $93.6 \pm 2.9$ & $419.3 \pm 16.8$ \\
\hline II & $\mathrm{CCl}_{4}(\mathrm{I} \mathrm{mL} / \mathrm{kg})$ & $127.6 \pm 5.7^{\$}$ & $98.4 \pm 4.4^{\$}$ & $201.8 \pm 8.2^{\$}$ & $994.5 \pm 26.8^{\$}$ \\
\hline III & Silymarin $(100 \mathrm{mg} / \mathrm{kg})+\mathrm{CCl}_{4}(1 \mathrm{~mL} / \mathrm{kg})$ & $53.7 \pm 4.2 *$ & $49.3 \pm 2.9 *$ & $114.6 \pm 6.4 *$ & $485.1 \pm 15.7^{*}$ \\
\hline IV & SGNPs $(10 \mathrm{mg} / \mathrm{kg})+\mathrm{CCl}_{4}(1 \mathrm{~mL} / \mathrm{kg})$ & $58.3 \pm 3.8^{*}$ & $52.5 \pm 2.7^{*}$ & $118.2 \pm 7.6^{*}$ & $518.4 \pm 13.8^{*}$ \\
\hline $\mathrm{V}$ & SGNPs $(20 \mathrm{mg} / \mathrm{kg})+\mathrm{CCl}_{4}(\mathrm{I} \mathrm{mL} / \mathrm{kg})$ & $46.7 \pm 3.3^{*}$ & $44.2 \pm 2.6 *$ & $103.4 \pm 7.5^{* \wedge}$ & $458.6 \pm \mid 4.7^{* \wedge}$ \\
\hline VI & GSGNPs $(10 \mathrm{mg} / \mathrm{kg})+\mathrm{CCl}_{4}(\mathrm{I} \mathrm{mL} / \mathrm{kg})$ & $48.8 \pm 3 . I^{*}$ & $47.1 \pm 3.7^{*}$ & $107.6 \pm 6.8 *$ & $463.4 \pm 15.2^{*}$ \\
\hline VII & GSGNPs $(20 \mathrm{mg} / \mathrm{kg})+\mathrm{CCl}_{4}(\mathrm{I} \mathrm{mL} / \mathrm{kg})$ & $41.6 \pm 2.6^{* \wedge}$ & $40.3 \pm 2.3^{* \wedge}$ & $97.4 \pm 5.9 * \wedge$ & $434.8 \pm 13.4^{* \wedge}$ \\
\hline
\end{tabular}

Notes: All the results are expressed as mean \pm SD $(n=6) .{ }^{\$ P}<0.05$, comparison of Group II with Group I. *P<0.05, comparison of Groups III-VII with Group II. ^P<0.05, comparison of Groups IV-VII with Group III.

Abbreviations: AST, aspartate transferase; ALT, alanine transaminase; ALP, alkaline phosphatase; LDH, lactate dehydrogenase; DW, distilled water; SGNPs, silymarintethered gold nanoparticles; GSGNPs, SGNPs aggregated in glycogen.

\section{Hepatoprotective ability of nanohybrids in $\mathrm{CCl}_{4}$-intoxicated rats}

\section{Effect on serum biochemical enzymes}

Liver function in terms of serum biochemical markers was estimated to evaluate the liver-protective ability of SGNPs and GSGNPs. Table 1 depicts the levels of AST, ALT, ALP, and $\mathrm{LDH}$ in animals treated with $\mathrm{CCl}_{4}$ and various drugs. $\mathrm{CCl}_{4}$ injection to the animals caused a significant increase in all these enzyme levels compared to normal animals. Animals treated with Sly, SGNPs, and GSGNPs exhibited significant protection against the $\mathrm{CCl}_{4}$ where restoration of these markers to normal levels was observed. SGNPs and GSGNPs showed potent response than Sly, and the latter one was more potent than the former. The results of this study confirmed that Gly-gold nanohybrid system enhanced the potency of Sly.

Effect on liver antioxidant enzyme levels and lipid peroxidation

SOD and CAT are the two antioxidant enzymes responsible for decomposition of free radicals generated in the body. The $\mathrm{CCl}_{4}$ treatment causes collapse of antioxidant defense mechanism and leads to subsequent rise and accumulation of free radicals. Binding of these radicals to membrane lipids induces lipid peroxidation (LPO) and damages the cells. Here, $\mathrm{CCl}_{4}$ injection caused a significant increase in the LPO and decline in the SOD and CAT levels. Animals treated with Sly, SGNPs, and GSGNPs showed significant protection against $\mathrm{CCl}_{4}$ in a dose-dependent manner. Both SGNPs and GSGNPs showed potent response than Sly, and GSGNPs showed superior response. These results further support the potency enhancement of Sly due to functionalization of the same in Gly-gold nanohybrid system (Table 2).

\section{Effect of drug treatment on serum inflammatory cytokines levels}

Animals treated with $\mathrm{CCl}_{4}$ showed a significant increase $(P<0.05)$ in inflammatory cytokines (tumor necrosis factor- $\alpha[$ TNF- $\alpha]$ and interleukin- $1 \beta$ [IL-1 $\beta])$ compared to normal animals. Sly showed significant protection against the $\mathrm{CCl}_{4}$-mediated raise in these inflammatory markers. No significant difference in controlling IL-1 $\beta$ was observed in animals treated with SGNPs $(10 \mathrm{mg} / \mathrm{kg})$ compared to Sly, whereas all the other treatment groups (SGNPs $20 \mathrm{mg} / \mathrm{kg}$, GSGNPs 10 and $20 \mathrm{mg} / \mathrm{kg}$ ) showed a significant difference. In the case of TNF- $\alpha$ except for GSGNPs $20 \mathrm{mg} / \mathrm{kg}$, no other

Table 2 Effect of different drug treatments on liver antioxidant enzymes and lipid peroxidation levels in $\mathrm{CCl}_{4}$-intoxicated rats

\begin{tabular}{|c|c|c|c|c|}
\hline Group & Treatment & $\operatorname{SOD}(\mathrm{U} / \mathrm{mL})$ & CAT (nmol/min/mL) & TBARS (nmol/g tissue) \\
\hline $\mathrm{I}$ & DW + olive oil (I mL/kg) & $10.6 \pm 1.2$ & $6.1 \pm 0.7$ & $145.3 \pm 6.9$ \\
\hline ॥ & $\mathrm{CCl}_{4}(\mathrm{I} \mathrm{mL} / \mathrm{kg})$ & $1.8 \pm 0.3^{\$}$ & $1.1 \pm 0.1^{\$}$ & $364.85 \pm 9.6^{\$}$ \\
\hline III & Silymarin $(100 \mathrm{mg} / \mathrm{kg})+\mathrm{CCl}_{4}(\mathrm{I} \mathrm{mL} / \mathrm{kg})$ & $7.5 \pm 0.7^{*}$ & $4.4 \pm 0.6 *$ & $178.3 \pm 7.6 *$ \\
\hline IV & SGNPs $(10 \mathrm{mg} / \mathrm{kg})+\mathrm{CCl}_{4}(\mathrm{I} \mathrm{mL} / \mathrm{kg})$ & $6.7 \pm 0.6^{*}$ & $3.9 \pm 0.5^{*}$ & $182.8 \pm 8.3^{*}$ \\
\hline 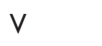 & SGNPs $(20 \mathrm{mg} / \mathrm{kg})+\mathrm{CCl}_{4}(\mathrm{I} \mathrm{mL} / \mathrm{kg})$ & $8.5 \pm 0.8^{*}$ & $5.3 \pm 0.6 *$ & $159.1 \pm 7.4^{*, \wedge}$ \\
\hline VI & GSGNPs $(10 \mathrm{mg} / \mathrm{kg})+\mathrm{CCl}_{4}(\mathrm{I} \mathrm{mL} / \mathrm{kg})$ & $8.3 \pm 0.7^{*}$ & $4.9 \pm 0.4^{*}$ & $163.8 \pm 8.1 *$ \\
\hline VII & GSGNPs $(20 \mathrm{mg} / \mathrm{kg})+\mathrm{CCl}_{4}(\mathrm{I} \mathrm{mL} / \mathrm{kg})$ & $9.6 \pm 0.8^{*, \Lambda}$ & $5.8 \pm 0.6 *, \Lambda$ & $152.5 \pm 7.7^{*, \Lambda}$ \\
\hline
\end{tabular}

Notes: All the results are expressed as mean \pm SD $(n=6)$. ${ }^{\$ P}<0.05$, comparison of Group II with Group I. *P<0.05, comparison of Groups III-VII with Group II. $\wedge^{\wedge}<0.05$, comparison of Groups IV-VII with Group III.

Abbreviations: SOD, superoxide dismutase; CAT, catalase; TBARS, thiobarbituric acid-reacting substance; DW, distilled water; SGNPs, silymarin-tethered gold nanoparticles; GSGNPs, SGNPs aggregated in glycogen. 
treatment groups showed a significant difference compared to Sly-treated animals. The results of this study explain that SGNPs and GSGNPs are potent than Sly in controlling the inflammatory markers (Figure 5A and B).

\section{Determination of gold ion concentration in liver}

At the end of the drug treatment period, the gold ion concentration in the liver was determined by GF-AAS analysis. Animals treated with SGNPs $(20 \mathrm{mg} / \mathrm{kg})$ showed accumulation of $1.2 \mu \mathrm{g}$ of GNPs/g of liver tissue, whereas animals treated with GSGNPs $(20 \mathrm{mg} / \mathrm{kg}$ ) showed accumulation of $2.3 \mu \mathrm{g}$ of GNPs/g in the liver. The results of this study confirm the proficient hepatic delivery of GSGNPs over SGNPs.

\section{Histopathology of liver tissue from various treatment groups}

Liver histology from various treatment groups supported the in vivo biochemical experimental results. Animals in the control group showed hepatocytes with normal texture with no cell infiltrate. $\mathrm{CCl}_{4}$ treatment produced significant damage to the liver physiology where the histology results showed the formation of bridging necrosis with demolished hepatocytes and chronic cell infiltrate. Animals treated with Sly, SGNPs, and GSGNPs showed normal liver physiology where the former one showed very mild inflammatory cells ( $4 \%)$. The results of this study demonstrate the hepatoprotective ability of the SGNPs and GSGNPs (Figure 6A-G).

\section{Plasma concentration of Sly in various treatment groups}

Sly concentration in plasma at different time intervals after oral administration with different formulations (free Sly, commercial Sly product, SGNPs, and GSGNPs) is illustrated in Figure 7. Peak plasma concentrations $\left(C_{\max }\right)$ of Sly in various treatment groups are summarized in Table $\mathrm{S} 1$. No significant difference was observed in the $C_{\max }$ and $T_{\max }$ between animals treated with free Sly and commercial Sly
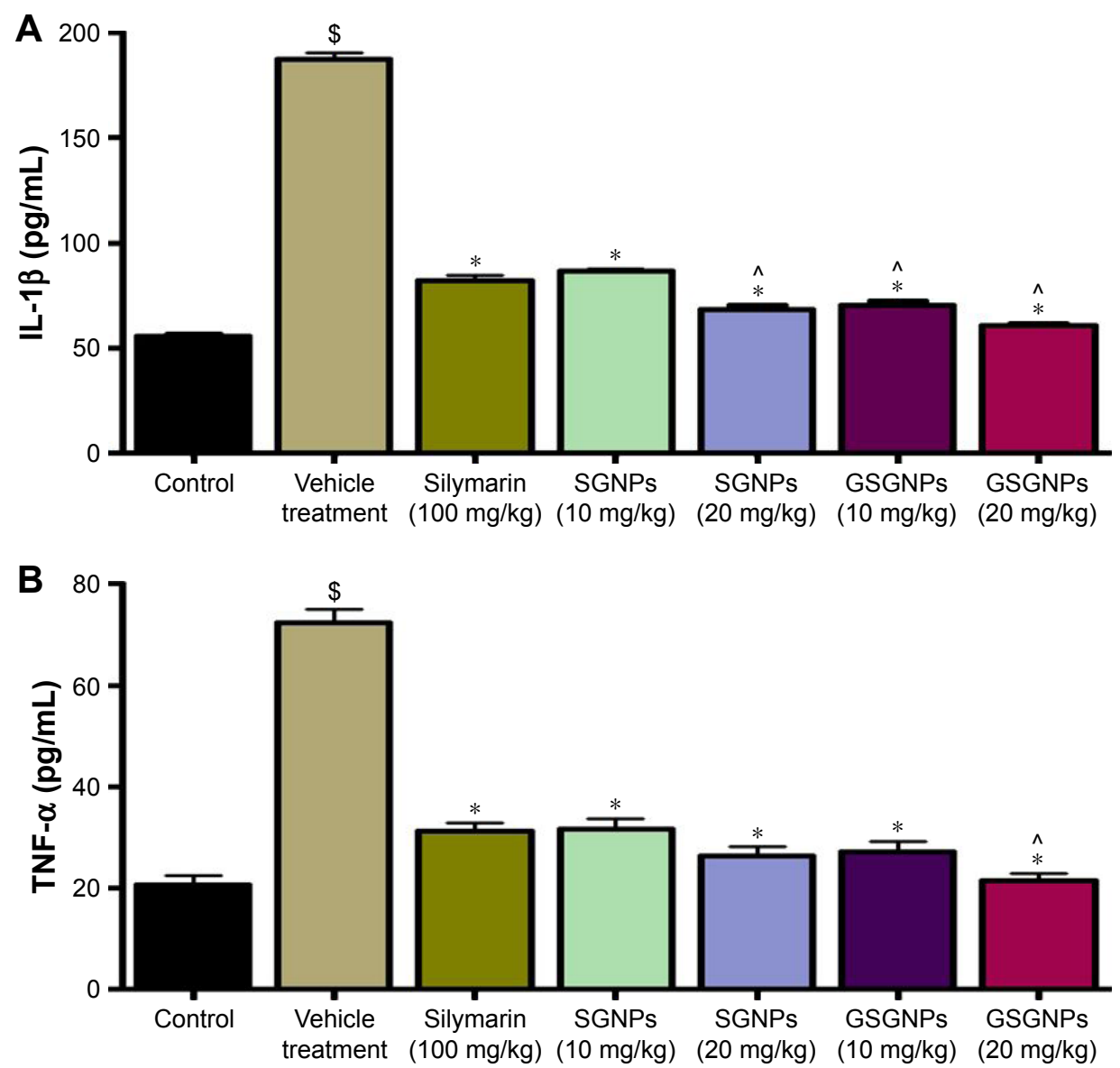

Figure 5 Effect of various treatments on serum (A) IL-I $\beta$ and (B) TNF- $\alpha$ levels. All the results are expressed as mean $\pm S D$ ( $n=6$ ). ${ }^{\$ P}<0.05$, comparison of vehicle treatment with control; $* P<0.05$, comparison of silymarin, SGNPs, and GSGNPs treatment with vehicle treatment; $\wedge P<0.05$, comparison of $S G N P s$ and GSGNPs treatment with silymarin treatment.

Abbreviations: IL-I $\beta$, interleukin-I $\beta$; TNF- $\alpha$, tumor necrosis factor- $\alpha$; SGNPs, silymarin-tethered gold nanoparticles; GSGNPs, SGNPs aggregated in glycogen. 

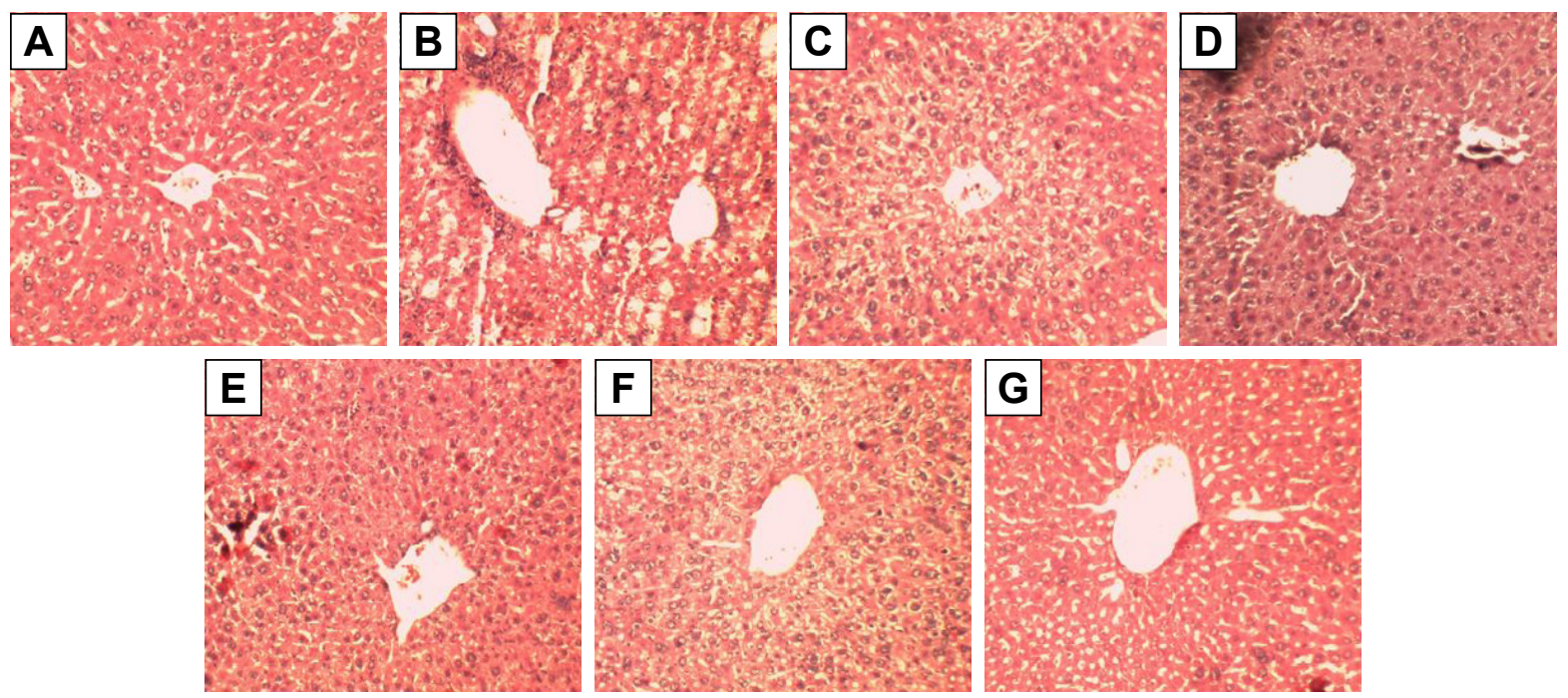

Figure 6 Histopathology of the liver tissue from different treatment groups: (A) control group showing normal liver tissue with no inflammation and necrosis; (B) group treated with $\mathrm{CCl}_{4}$ alone showed necrosis and inflammatory cells; (C) group treated with $\mathrm{CCl}_{4}$ and silymarin $100 \mathrm{mg} / \mathrm{kg}$; (D and E) groups treated with SGNPs 10 and $20 \mathrm{mg} / \mathrm{kg}$, respectively; (F and G) groups treated with GSGNPs 10 and $20 \mathrm{mg} / \mathrm{kg}$, respectively, showing normal liver morphology with no necrosis and inflammation. Magnification $10 \times$. Abbreviations: SGNPs, silymarin-tethered gold nanoparticles; GSGNPs, SGNPs aggregated in glycogen.

product, whereas SGNPs- and GSGNPs-treated animals showed significant increase in the $C_{\max }$ and $T_{\max }$ compared to those treated with free Sly. These data revealed that SGNPs and GSGNPs facilitate Sly absorption for prolonged duration compared to free Sly or commercial Sly product. Moreover, the longer $T_{\max }$ observed for GSGNPs may be related to their better self-stability compared to SGNPs. The observation revealed that, compared to the free Sly, the commercial Sly product increased the $C_{\max }$ by 1.08 -fold, while the SGNPs caused 1.54-fold increment. Most importantly, the GSGNPs administration demonstrated a 2.0 -fold increase in $C_{\max }$.

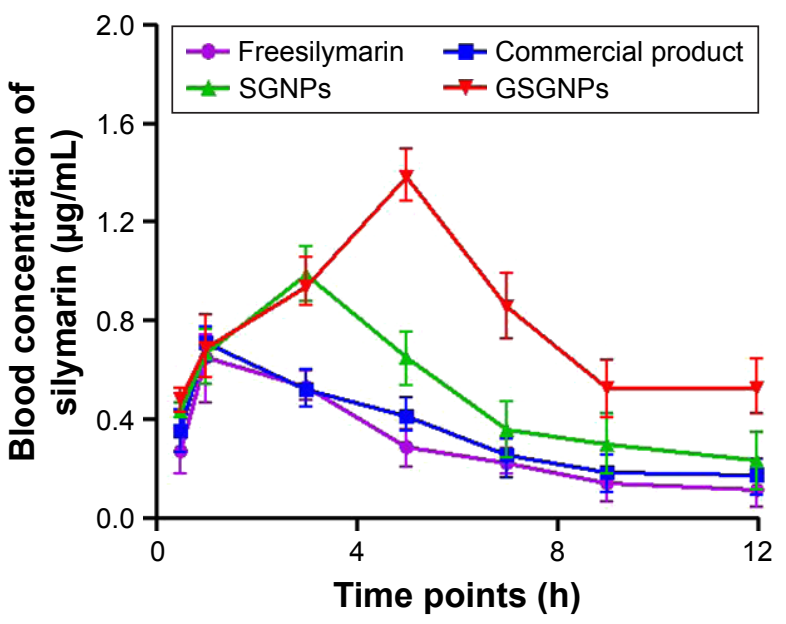

Figure 7 Plasma concentration of silymarin in various treatment groups at different time points.

Abbreviations: SGNPs, silymarin-tethered gold nanoparticles; GSGNPs, SGNPs aggregated in glycogen.
These findings indicated that GSGNPs could provide a promising strategy for improving the bioavailability of Sly. The enhanced bioavailability of Sly delivered by these nanohybrids could be attributed to their improved rate of solubility, enhanced gut permeation, and stability.

\section{Storage stability of nanohybrids}

The nanohybrids (GSGNPs) maintained their initial size after 6 months of storage at different temperatures $\left(4^{\circ} \mathrm{C}\right.$ and $25^{\circ} \mathrm{C}$ ). These results support the stability of the prepared nanohybrids, which is an ideal characteristic of the drug.

\section{Discussion}

Sly is a flavonoid complex derived from Silybum marianum seed milk extract which is a well-known antioxidant and hepatoprotective agent. Its water solubility is low, yet Sly does not possess lipophilic properties. Gut absorption of the Sly $(20 \%-40 \%)$ is very low resulting in its poor bioavailability as a drug. ${ }^{30}$ In this study, we synthesized a nanohybrid by tethering the Sly molecule on GNPs (SGNPs) and aggregated in Gly matrix (GSGNPs). In the process of synthesizing SGNPs, we utilized $A$. reticulata leaf aqueous extract as a reducing agent for the generation of GNPs from the reduction process. In fact, phytochemicals such as flavonoids, phenolic compounds, and alkaloids present in the $A$. reticulata leaves acted as reducing and stabilizing agents for the synthesis of SGNPs. The successful formation of the SGNPs and GSGNPs was confirmed by the UV-Vis 
spectroscopy, FT-IR spectroscopy, and XRD analysis. Gly is a polysaccharide containing highly branched glucose molecules. The liver is the main storage organ for the Gly, and very minute levels are stored in skeletal muscles. Liver Gly comprises clusters of $\alpha$ particles formed from supramolecular $\beta$ particles. ${ }^{31}$ Morphology of nanosized $\beta$ particles of Gly plays a vital role in aggregation of SGNPs and influences the gut absorption of GSGNPs.

Prior to any application of this nanohybrid system in preclinical settings, it is important to study the tolerance of the mammalian cells to a higher dose to standardize the biosafe concentration for future biomedical applications. RBC constitutes $40 \%-50 \%(\mathrm{v} / \mathrm{v})$ of human whole blood and is responsible for transport of carbon dioxide and oxygen. Hemolysis refers to release of hemoglobin due to the disintegration of the three-layered RBC membrane, which has been considered as a pivotal parameter for biocompatibility assessment of blood-contacting biomaterials. In this study, the prepared nanohybrids (GSGNPs) were found to be biocompatible, whereas at higher concentration, very mild hemolysis was observed, which was in the permeable limit (5\%). ${ }^{32}$ Further, FE-SEM analysis confirmed that RBCs maintain their membrane integrity even after treatment with a high concentration ( $1 \mathrm{mg} / \mathrm{mL}$ ) of GSGNPs for $24 \mathrm{~h}$. Treatment of SGNPs and GSGNPs did not induce any toxic effect toward the L929 cells at different concentrations $(5-250 \mu \mathrm{g} / \mathrm{mL})$. The results of this study demonstrated that both SGNPs and GSGNPs do not possess any toxic chemical groups to cause damage to the mammalian cells.

Both SGNPs and GSGNPs were evaluated for hepatoprotective ability against $\mathrm{CCl}_{4}$-induced hepatic damage in the rats and compared with standard Sly. $\mathrm{CCl}_{4}$ is a well-known hepatotoxic agent that converts into $\mathrm{CCl}_{3} \cdot$ radical, which covalently binds to the sulfhydryl groups of cell proteins' thiol moiety and causes membrane LPO with necrosis of hepatocytes. The products of LPO bind to the DNA and form the mutagenic pirimedopurinone adduct of deoxyguanosine (M1G), which causes oxidative damage to the DNA. Earlier reports suggested that $\mathrm{CCl}_{4}$ indirectly activates Kupffer cells, neutrophils, and macrophages, which stimulate the production of inflammatory cytokines and free radicals. Stimulation of inflammatory cytokines like TNF- $\alpha$ and IL-1 $\beta$ causes prostaglandin production, neutrophil infiltration, and necrosis to hepatocytes. ${ }^{33}$ The necrotic hepatocyte releases hepatobiliary enzymes like AST, ALT, ALP, and LDH into the bloodstream. ${ }^{24,25}$ Antioxidant defense enzymes (SOD and CAT) neutralize the ROS produced in the body. SOD putrefies the highly reactive superoxide radical $\left(\mathrm{O}_{2} \cdot^{-}\right)$into hydrogen peroxide $\left(\mathrm{H}_{2} \mathrm{O}_{2}\right)$, which further converts it to water in the presence of CAT. $\mathrm{CCl}_{4}$ treatment depletes these antioxidant defense enzymes and leads to pronounced increase in oxidative damage to the hepatocytes. Sly $(100 \mathrm{mg} / \mathrm{kg})$, SGNP (10 and $20 \mathrm{mg} / \mathrm{kg}$ ), and GSGNP (10 and $20 \mathrm{mg} / \mathrm{kg}$ ) treatments showed significant protection against $\mathrm{CCl}_{4}$ as evident from restoration of normal enzyme levels. Antioxidant molecules play a major role in controlling the oxidative damagemediated liver diseases. Sly is a flavonolignan antioxidant widely used for the treatment of liver ailments. It neutralizes the free radicals formed by LPO, thereby inhibiting the DNA damage and attenuation of inflammatory mediators, and also stabilizing the cell membrane of the hepatocytes. This action is attributed to the reduced levels of hepatobiliary enzyme leakage from hepatocytes. In general, poor solubility, less stability in gastric juices, and low gut absorption have hindered the Sly use and driven patients for large dose. In this study, GSGNPs showed potent hepatoprotective response compared to SGNPs and free Sly. However, SGNPs were found to be potent compared to free Sly, which was supported by the previous studies. ${ }^{2}$ SGNPs and GSGNPs are soluble in water, whereas free Sly is not freely soluble. Nanoparticulate Sly was reported to produce a pronounced increase in bioavailability and biological activity due to its increased solubility. ${ }^{2,34}$ Previous reports suggested that functionalization of Sly on GNPs ameliorates the hepatic damage through downregulating the liver stellate cells and attenuating Kupffer cells. ${ }^{2}$ Presence of Gly enhanced the gut permeation of the GSGNPs and guided toward the liver. The enhanced plasma concentration $\left(C_{\max }\right)$ of Sly in GSGNP-treated rats compared to free Sly- and commercial Sly product-treated rats revealed the enhanced gut permeation and potency of reported nanohybrid system. We hypothesize that Gly hydrolyzes in the small intestine which creates a sugar cloud and absorbs at a faster rate due to osmosis effect, which enhanced the gut permeation of the drug. Further, the presence of Gly enhances the solubility of the Sly and protects the same from acidic degradation in gastric juices. Increased $T_{\max }$ of the Sly in GSGNP-treated animals is due to its longer stability in the physiological system compared to free Sly-treated animals. The AAS of liver tissue supports the proficient delivery ability of GSGNPs. The findings of this study suggest that GSGNPs are potent than Sly due to their enhanced solubility and bioavailability, which was further supported by histopathology analysis of liver tissue. The proposed mechanism of action of the prepared nanohybrids is depicted in Figure 8. 


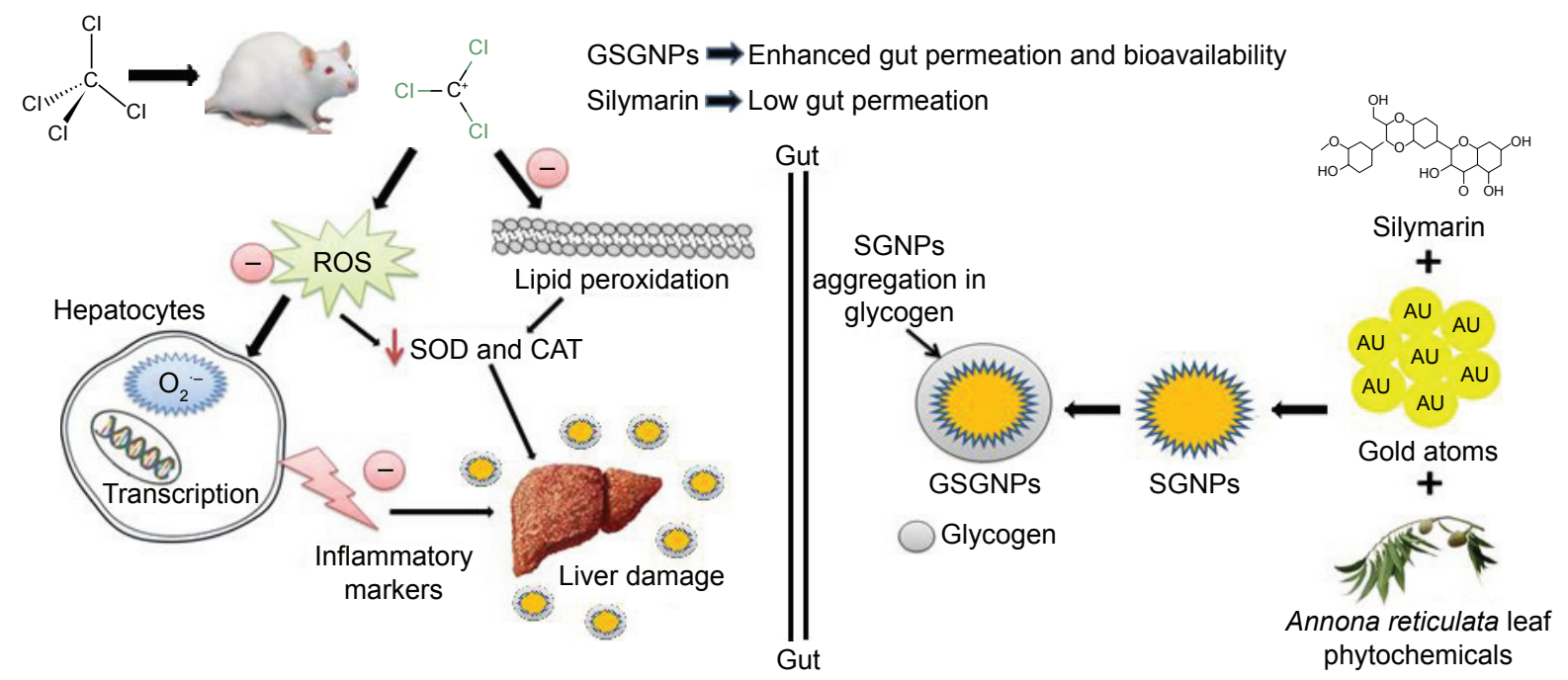

Figure 8 Schematic representation of the mode of action of GSGNPs.

Abbreviations: GSGNPs, SGNPs aggregated in glycogen; ROS, reactive oxygen species; SOD, superoxide dismutase; CAT, catalase; SGNPs, silymarin-tethered gold nanoparticles.

\section{Conclusion}

We have demonstrated the successful fabrication of a novel biocompatible Gly-gold nanohybrid to enhance the bioavailability of poorly water-soluble drugs like Sly. In this study, Sly has been tethered on gold nanoparticle surface and aggregated into Gly matrix to fabricate a nanohybrid. We elucidated the positive attributes of the therapeutic nanohybrid system as an efficient hepatoprotective agent against liver injury caused by toxins. Compared to free Sly, GSGNPs exhibited significant hepatoprotection with tenfold increase in the potency due to increased solubility, bioavailability, and profuse gut absorption. The findings of this study describe the positive traits of the Gly-gold nanohybrid drug delivery system for enhancing the bioavailability of therapeutic molecules, which open up an avenue for translational research in this direction.

\section{Acknowledgments}

The authors would like to thank the Department of Science and Technology (DST), Government of India, New Delhi, India, for financial support. They extend their gratitude to Mr Bikash Sharma for his help in conducting the FE-SEM analysis. They would like to thank Ms Bhupalee Kalita for helping in the correction of English language of the manuscript.

\section{Author contributions}

RK and SK conceptualized the study, and designed and conducted the experiments. RK wrote the manuscript. ACB and S Kundu preformed and analyzed the characterization experiments. SD, JK, and NCT supervised the work and approved the manuscript. All authors contributed toward data analysis, drafting and critically revising the paper and agree to be accountable for all aspects of the work.

\section{Disclosure}

The authors report no conflict of interest in this work.

\section{References}

1. Hou F, Zhang R, Zhang M, et al. Hepatoprotective and antioxidant activity of anthocyanins in black rice bran on carbon tetrachlorideinduced liver injury in mice. J Funct Foods. 2013;5(4):1705-1713.

2. Kabir N, Ali H, Ateeq M, Bertino MF, Shah MR, Franzel L. Silymarin coated gold nanoparticles ameliorates $\mathrm{CCl} 4$-induced hepatic injury and cirrhosis through down regulation of hepatic stellate cells and attenuation of Kupffer cells. RSC Adv. 2014;4:9012-9020.

3. Zhao X, Deng Y, Zhang Y, et al. Silymarin nanoparticles through emulsion solvent evaporation method for oral delivery with high antioxidant activities, bioavailability, and absorption in the liver. RSC Adv. 2016; 6(95): 93137-93146.

4. Das S, Roy P, Auddy RG, Mukherjee A. Silymarin nanoparticle prevents paracetamol-induced hepatotoxicity. Int J Nanomedicine. 2011;6: 1291-1301.

5. Kreyling WG, Abdelmonem AM, Ali Z, et al. In vivo integrity of polymer-coated gold nanoparticles. Nat Nanotechnol. 2015;10(7): 619-623.

6. Bozanic DK, Luyt AS, Trandafilovic LV, Djoković V. Glycogen and gold nanoparticle bioconjugates: controlled plasmon resonance via glycogen-induced nanoparticle aggregation. RSC Adv. 2013;3(23): 8705-8713.

7. Li X, Robinson SM, Gupta A, et al. Functional gold nanoparticles as potent antimicrobial agents against multi-drug-resistant bacteria. ACS Nano. 2014;8(10):10682-10686.

8. Sánchez-Paradinas S, Pérez-Andrés M, Almendral-Parra MJ, et al. Enhanced cytotoxic activity of bile acid cisplatin derivatives by conjugation with gold nanoparticles. J Inorg Biochem. 2012;131:8-11.

9. Jain S, Hirst DG, O'Sullivan JM. Gold nanoparticles as novel agents for cancer therapy. Br J Radiol. 2012;85(1010):101-113.

10. Elia P, Zach R, Hazan S, Kolusheva S, Porat ZE, Zeiri Y. Green synthesis of gold nanoparticles using plant extracts as reducing agents. Int $J$ Nanomedicine. 2014;9:4007-4021. 
11. Sharma RK, Gulati S, Mehta S. Preparation of gold nanoparticles using tea: a green chemistry experiment. J Chem Educ. 2012;89(10): 1316-1318.

12. Suman TY, Rajasree SR, Ramkumar R, Rajthilak C, Perumal P. The green synthesis of gold nanoparticles using an aqueous root extract of Morinda citrifolia L. Spectrochim Acta A Mol Biomol Spectrosc. 2014;118:11-16.

13. Siddiqi KS, Husen A. Recent advances in plant-mediated engineered gold nanoparticles and their application in biological system. J Trace Elem Med Biol. 2017;40:10-23.

14. Jamkhande PG, Wattamwar AS, Kankudte AD, Tidke PS, Kalaskar MG. Assessment of Annona reticulata Linn. leaves fractions for in-vitro antioxidative effect and antimicrobial potential against standard human pathogenic strains. Alexandria J Med. 2016;52(1):19-25.

15. Wele A, Mayer C, Quentin D, Zhang Y, Blond A, Bodo B. 3D-structure of cycloreticulin $\mathrm{C}$ and glabrin A, cyclopeptides from the seeds of Annona reticulata. Tetrahedron. 2009;65(1):275-281.

16. Chang FR, Chen JL, Chiu HF, Wu MJ, Wu YC. Acetogenins from seeds of Annona reticulata. Phytochemistry. 1998;47(6):1057-1061.

17. Wele A, Mayer C, Dermigny Q, Zhang Y, Blond A, Bodo B. Sequence and three dimensional structure of cycloreticulins $\mathrm{A}$ and $\mathrm{B}$ new cyclooctapeptides from the seeds of Annona reticulata. Tetrahedron. 2008;64(1):154-162.

18. Bozanic DK, Brankovic SD, Bibic N, Luyt AS, Djoković V. Silver nanoparticles encapsulated in glycogen biopolymer: morphology, optical and antimicrobial properties. Carbohydr Polym. 2011;83(2): 883-890.

19. Madhusudhan A, Reddy GB, Venkatesham M, et al. Efficient pH dependent drug delivery to target cancer cells by gold nanoparticles capped with carboxymethyl chitosan. Int J Mol Sci. 2014;15(5):8216-8234.

20. Kalita S, Devi B, Kandimalla R, et al. Chloramphenicol encapsulated in poly- $\varepsilon$-caprolactone-pluronic composite: nanoparticles for treatment of MRSA-infected burn wounds. Int J Nanomedicine. 2015;10 2971-2984.

21. Kalita S, Kandimalla R, Devi B, et al. Dual delivery of chloramphenicol and essential oil by poly- $\varepsilon$-caprolactone-Pluronic nanocapsules to treat MRSA-Candida co-infected chronic burn wounds. RSC Adv. 2017; 7: 1749-1758.

22. Kandimalla R, Kalita S, Choudhury B, et al. Fiber from ramie plant (Boehmeria nivea): a novel suture biomaterial. Mater Sci Eng C Mater Biol Appl. 2016;62:816-822.
23. Kalita S, Kandimalla R, Sharma KK, Kataki AC, Deka M, Kotoky J. Amoxicillin functionalized gold nanoparticles reverts MRSA resistance. Mater Sci Eng C. 2016;61:720-727.

24. Kandimalla R, Dash S, Kalita S, et al. Protective effect of bioactivity guided fractions of Ziziphus jujuba Mill. root bark against hepatic injury and chronic inflammation via inhibiting inflammatory markers and oxidative stress. Front Pharmacol. 2016;7:298.

25. Kandimalla R, Dash S, Kalita S, et al. Bioactive guided fractions of Annona reticulata L. bark: protection against liver toxicity and inflammation through inhibiting oxidative stress and proinflammatory cytokines. Front Pharmacol. 2016;7:168.

26. Kandimalla R, Dash S, Kalita S, et al. Bioactive fraction of Annona reticulata bark (or) Ziziphus jujuba root bark along with insulin attenuates painful diabetic neuropathy through inhibiting NF- $\kappa \mathrm{B}$ inflammatory cascade. Front Cell Neurosci. 2017;11:73.

27. Choudhury AJ, Gogoi D, Chutia J, et al. Controlled antibiotic-releasing Antheraea assama silk fibroin suture for infection prevention and fast wound healing. Surgery. 2016;159(2):539-547.

28. Bhardwaj N, Singh YP, Devi D, Kandimalla R, Kotoky J, Mandal BB. Potential of silk fibroin/chondrocyte constructs of muga silkworm Antheraea assamensis for cartilage tissue engineering. J Mater Chem B. 2016;4(21):3670-3684.

29. Yang G, Zhao Y, Feng N, Zhang Y, Liu Y, Dang B. Improved dissolution and bioavailability of silymarin delivered by a solid dispersion prepared using supercritical fluids. Asian J Pharm Sci. 2015;10(3):194-202.

30. Javed S, Kohli K, Ali M. Reassessing bioavailability of silymarin. Altern Med Rev. 2011;16(3):239-249.

31. Sullivan MA, Vilaplana F, Cave RA, Stapleton D, Gray-Weale AA, Gilbert RG. Nature of $\alpha$ and $\beta$ particles in glycogen using molecular size distributions. Biomacromolecules. 2010;11(4):1094-1100.

32. Choudhury AJ, Dolly G, Kandimalla R, et al. Penicillin impregnation on oxygen plasma surface functionalized chitosan/Antheraea assama silk fibroin: Studies of antibacterial activity and antithrombogenic property. Mater Sci Eng C Mater Biol Appl. 2016;60:475-484.

33. Horiguchi N, Lafdil F, Miller AM, et al. Dissociation between liver inflammation and hepatocellular damage induced by carbon tetrachloride in myeloid cell-specific signal transducer and activator of transcription 3 gene knockout mice. Hepatology. 2010;51(5):1724-1734.

34. Parveen R, Baboota S, Ali J, Ahuja A, Vasudev SS, Ahmad S. Oil based nanocarrier for improved oral delivery of silymarin: in vitro and in vivo studies. Int J Pharm. 2011;413(1-2):245-253. 


\section{Supplementary material}

Table SI Peak plasma concentration of silymarin in various treatment groups with respect to time

\begin{tabular}{lll}
\hline Formulation of silymarin & $\boldsymbol{C}_{\max }(\mu \mathrm{g} / \mathrm{mL})$ & $\boldsymbol{T}_{\max }(\mathbf{h})$ \\
\hline Silymarin powder & $0.672 \pm 0.141$ & $1.44 \mathrm{I} \pm 0.315$ \\
Commercial product & $0.726 \pm 0.094$ & $1.215 \pm 0.217$ \\
SGNPs & $1.037 \pm 0.116^{*}$ & $3.246 \pm 0.148^{*}$ \\
GSGNPs & $1.357 \pm 0.128^{*}$ & $4.959 \pm 0.235^{*}$ \\
\hline
\end{tabular}

Notes: All the results are expressed as mean \pm SD. $* P<0.05$ in comparison to silymarin powder treatment.

Abbreviations: SGNPs, silymarin-tethered gold nanoparticles; GSGNPs, SGNPs aggregated in glycogen.

\section{Publish your work in this journal}

The International Journal of Nanomedicine is an international, peerreviewed journal focusing on the application of nanotechnology in diagnostics, therapeutics, and drug delivery systems throughout the biomedical field. This journal is indexed on PubMed Central, MedLine, CAS, SciSearch ${ }^{\circledR}$, Current Contents ${ }^{\circledR} /$ Clinical Medicine,

Journal Citation Reports/Science Edition, EMBase, Scopus and the Elsevier Bibliographic databases. The manuscript management system is completely online and includes a very quick and fair peer-review system, which is all easy to use. Visit http://www.dovepress.com/ testimonials.php to read real quotes from published authors.

Submit your manuscript here: http://www.dovepress.com/international-journal-of-nanomedicine-journal 